\title{
TREND KARAKTERISTIK DEMOGRAFI PASIEN SKIZOFRENIA DI RUMAH SAKIT JIWA PROVINSI BALI (2013-2018)
}

\author{
I Wayan Darsana*, Ni Luh Putu Suariyani \\ Program Studi Kesehatan Masyarakat Fakultas Kedokteran Universitas Udayana \\ ${ }^{*}$ Email: darsana240296@gmail.com
}

\begin{abstract}
ABSTRAK
Skizofrenia di Indonesia berdasarkan hasil Riset Kesehatan Dasar tahun 2007, 2013 dan 2018 menunjukan bahwa prevalensi skizofrenia mengalami peningkatan dan penurunan yang fluktuatif. Penelitian ini bertujuan untuk melihat trend kesehatan jiwa (skizofrenia) di Rumah Sakit Jiwa (RSJ) Provinsi Bali berdasarkan karakteristik demografi periode 2013 - 2018. Penelitian ini merupakan penelitian deskriptif menggunakan rancangan longitudinal deskriptif study. Sampel dalam penelitian ini adalah seluruh pasien RSJ yang mengalami skizofrenia yang tercatat di register serta merupakan kasus baru periode 1 Januari 2013 - 31 Desember 2018. Karakteristik yang dicari dalam penelitian ini adalah umur, jenis kelamin, status perkawinan, pekerjaan, pendidikan, dan asal pasien. Pasien gangguan jiwa di RSJ Provinsi Bali selama enam tahun terakhir $64 \%$ nya merupakan pasien skizofrenia. Gangguan jiwa skizofrenia lebih banyak terjadi pada umur dewasa sebesar (58\%), berjenis kelamin laki-laki (66\%), sebanyak (58\%) tidak kawin, (88\%) tidak bekerja, tidak sekolah $(33 \%)$ dan asal pasien dari Kabupaten Gianyar sebanyak (16\%). Berdasarkan trend menunjukan bahwa trend kunjungan gangguan jiwa mengalami penurunan disetiap tahunnya, hanya mengalami peningkatan trend ditahun 2017 dan trend kembali turun ditahun 2018. Adanya penguatan sistem surveilans yang terpadu dan terintegrasi dari Puskesmas hingga RSJ Provinsi Bali sangat diperlukan agar data pasien gangguan jiwa skizofrenia menjadi lebih baik dan terintegrasi.
\end{abstract}

Kata kunci: Skizofrenia, Trend, Karakteristik

\begin{abstract}
Schizophrenia in Indonesia based on the results of Basic Health Research in 2007, 2013 and 2018 showed that the prevalence of schizophrenia had a fluctuating increase and decrease. This study aims to look at the trend of schizophrenia in the Mental Hospital (RSJ) of Bali Province based on the demographic characteristics of the period 2013 - 2018. This study was a descriptive study using a desain longitudinal study. The sample in this study were all RSJ patients who had schizophrenia recorded in the register and were new cases in the period 1 January 2013 - 31 December 2018. Characteristics sought in this study were age, sex, marital status, employment, education, and patient's origin. Mental patients in RSJ in Bali Province for the past six years 64\% were schizophrenic patients. Schizophrenia mental disorders occur more at the age of adults (58\%), male sex (66\%), as many $(58 \%)$ do not marry, $(88 \%)$ do not work, do not go to school (33\%) and the origin of patients from Gianyar Regency as much (16\%). There is an integrated and integrated surveillance system from the Health Service Center to the Provincial Hospital in Bali so that schizophrenic mental patients data get better and integrated.
\end{abstract}

Keywords: Skizofrenia, Trend, Characteristics

\section{PENDAHULUAN}

Gangguan jiwa skizofrenia adalah suatu jenis gangguan jiwa ditandai dengan perpecahan yang terjadi di dalam pikiran, perilaku dan perasaan (Pravitasari, 2015). Pedoman Penggolongan dan Diagnosis Gangguan Jiwa III mengklasifikasikan tipe skizofrenia menjadi 7 tipe, yang akan diuraikan sebagai berikut, Tipe Paranoid (F20.0), Tipe Hebefrenik (F20.1), Tipe
Katatonik (F20.2), Tipe Tak Terinci (F20.3), Tipe Residual (F20.5), Tipe Simpleks (F20.6) dan Tipe Depresi Pasca Skizofrenia (F20.4) (Videbeck, 2015; Pravitasari, 2015). Gejala skizofrenia dibagi kedalam 2 kategori, yaitu kategori gejala positif atau gejala nyata yang terdiri atas waham, halusinasi dan disorganisasi pikiran, bicara dan perilaku yang tidak teratur, sedangkan pada gejala negative atau gejala samar terdiri atas afek 
datar, tidak memiliki kemauan dan menarik diri dari masyarakat atau memiliki rasa tidak nyaman (Videbeck, 2015).

Data statistik yang disebutkan oleh World Health Organitation (WHO) pada tahun 2011 menunjukan bahwa penduduk di dunia yang mengalami gangguan jiwa sebesar 450 juta orang, dimana sepertiga dari jumlah tersebut terjadi di negara-negara yang berkembang. Selain itu WHO juga mengatakan bahwa potensi seseorang mengalami gangguan cukup tinggi, 1 diantara 4 orang mudah terserang gangguan jiwa (WHO, 2011). Selain itu data yang ada di Harvard University dan College London menyatakan bahwa penyakit kejiwaan ditahun 2016 dari semua jenis kecacatan di seluruh dunia memiliki peranan sebesar 32\% dan angka tersebut menglami peningkatan dari tahun sebelumnya (Nurmi, 2011).

Berdasarkan data Hasil Riset Kesehatan Dasar Tahun 2007, 2013 dan 2018 menunjukan di Indonesia gangguan jiwa dengan diagnosa skizofrenia memiliki prevalensi yang fluktuatif. Dimana ditahun 2007 prevalensi gangguan jiwa di Indonesia sebesar 4.1 per mil, ditahun 2013 mengalami penurunan menjadi 1.7 per mil dan rentang tahun 2013 - 2018 mengalami peningkatan 4 kali lipat selama 5 tahun terakhir menjadi 7 per mil. Provinsi Bali sebagai salah satu wilayah di Indonesia yang memiliki prevalensi ganguan jiwa tinggi menunjukan bahwa ditahun 2018 memiliki prevalensi sebesar 11 per mil atau lebih tinggi dari prevalensi nasional sebesar 4 per mil. Melihat perkembangan kasus gangguan jiwa skizofrenia maka pemerintah melalui salah satu indikator program Program Indonesia Sehat Berbasis Pendekatan Keluarga (PIS-
PK) berupaya untuk menemukan penderita gangguan jiwa agar mendapatkan pengobatan dan tidak ditelantarkan.

Hasil penelitian yang dilakukan sebelumnya menunjukan bahwa terdapat beberapa faktor risiko yang menyebabkan seseorang bisa mengalami skizofrenia disebabkan oleh faktor demografi yang terdiri atas, umur, jenis kelamin, status perkawinan, pendidikan, pekerjaan dan asal pasien. Menurut (Davies, 2009) menjelaskan bahwa secara sosio-demogrofi orang yang lebih rentan mengalami gangguan jiwa adalah berdasarkan umur berada pada kategori orang yang berumur dewasa, kemudian dari status perkawinan lebih rentan terjadi pada orang yang belum menikah, dari jenis kelamin seseorang yang rentan mengalami gangguan jiwa adalah berjenis kelamin laki-laki, berdasarkan status pekerjaan orang yang tidak bekerja memiliki kerentanan yang lebih dibandingkan dengan yang bekerja, serta orang yang berpendidikan rendah juga rentan bisa mengalami gangguan jiwa. Masih sangat terbatasnya data gangguan jiwa khususnya pada diagnosa skizofrenia di Provinsi Bali dan tingginya prevalensi gangguan jiwa di Provinsi Bali maka peneliti tertarik untuk melihat trend dan karakteristik pasien gangguan jiwa yang berobat di RSJ Provinsi Bali selama 6 tahun terakhir.

\section{METODE PENELITIAN}

Penelitian ini menggunakan desain penelitian longitudinal deskriptif. Dalam penelitian ini peneliti bertujuan untuk melihat trend pasien gangguan jiwa dengan 
diagnosa skizofrenia di RSJ Provinsi Bali periode 2013 -2018 dengan menggunakan data sekunder yaitu data registrasi pasien di bagian Rekam Medis RSJ Provinsi Bali. Dalam penelitian ini yang menjadi populasi target adalah seluruh pasien gangguan jiwa di RSJ Provinsi Bali. Sedangkan populasi terjangkau dalam penelitian ini adalah pasien gangguan jiwa di RSJ Provinsi Bali dari tanggal 1 Januari 2013 sampai dengan 31 Desember 2018. Sampel dalam penelitian ini adalah seluruh pasien RSJ yang tercatat di Data Register Rumah Sakit dan merupakan kasus baru periode 1 Januari 2013 - 31 Desember 2018. Variabel dalam penelitian ini adalah skizofrenia, umur, jenis kelamin, status perkawinan, pendidikan, pekerjaan, asal pasien dan tahun terdiagnosa. Selanjutnya data dianalisis untuk melihat trend skizofrenia di RSJ Provinsi Bali.

\section{HASIL PENELITIAN}

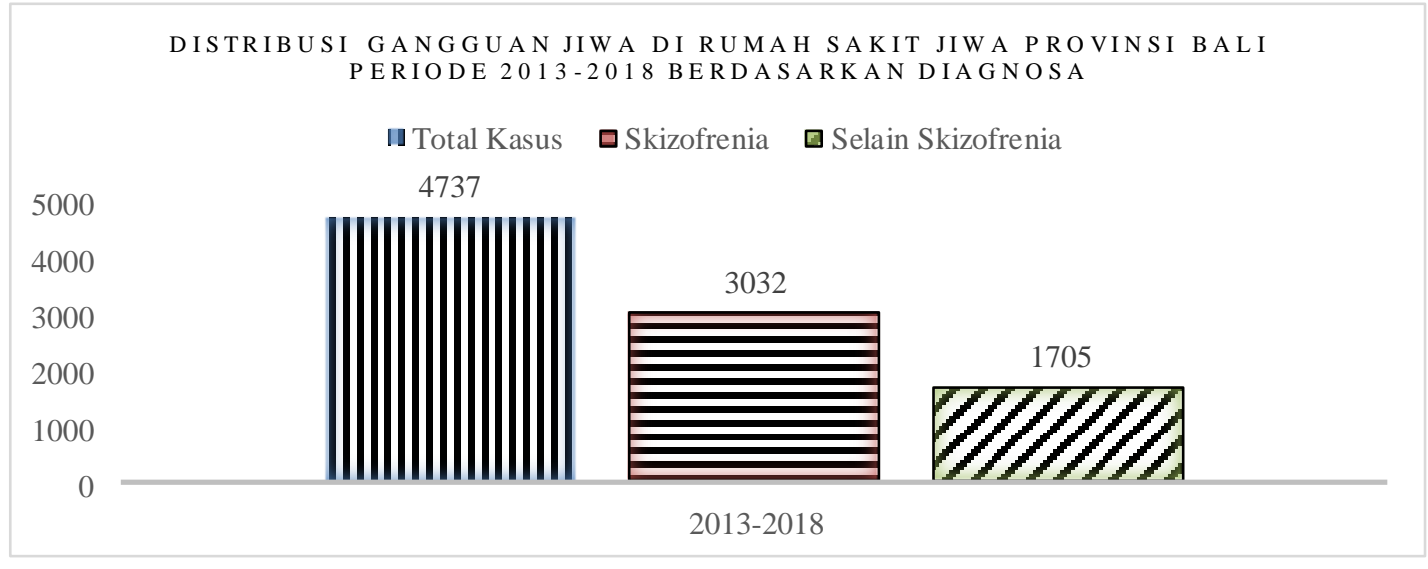

Dalam kurun waktu 6 tahun terakhir dari tanggal 1 Januari 2013 sampai dengan 31 Desember 2018 pasien gangguan jiwa baru yang berobat di RSJ Provinsi Bali berjumlah sebanyak 4737 pasien dimana 64\% dari pasien gangguan jiwa yang berobat merupakan pasien dengan diagnosa skizofrenia. 
Gambar 2. Trend Kunjungan Pasien Gangguan Jiwa di Rumah Sakit Jiwa Provinsi Bali

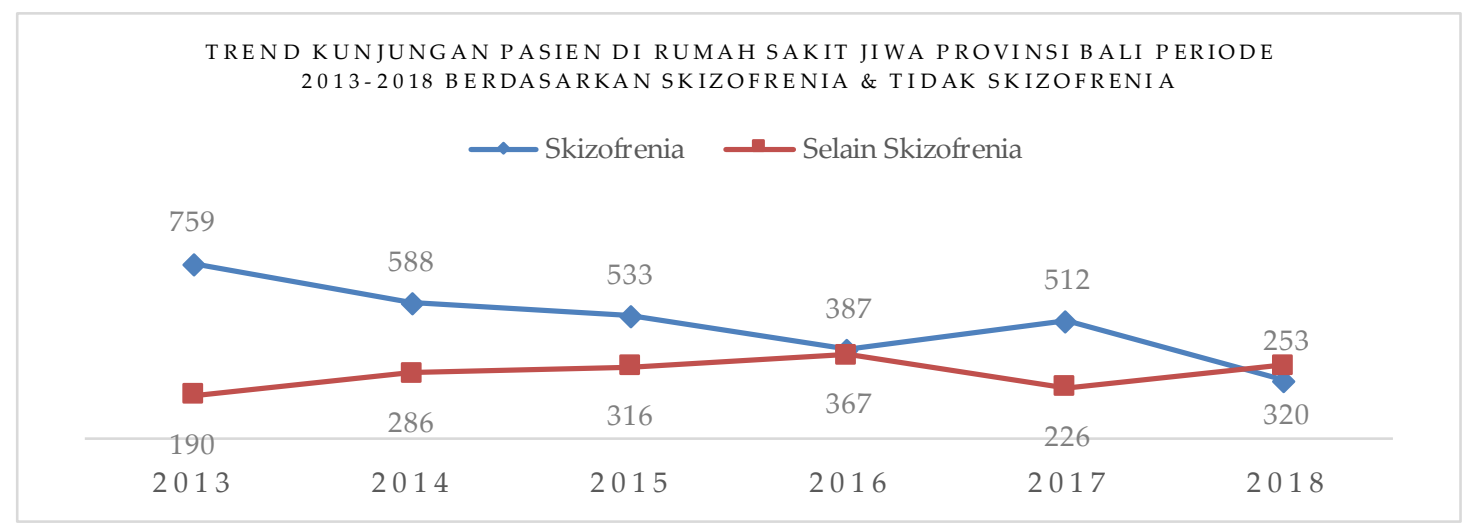

Jika dilihat trend secara umum pada menurun kemudian ditahun 2017 trend pasien skizofrenia menunjukan hasil bahwa mengalami peningkatan dan ditahun 2018 ditahun 2013 - 2016 terjadi trend yang trend kembali mengalami penurunan.

Tabel 3. Karakteristik Pasien Skizofrenia di Rumah Sakit Jiwa Provinsi Bali

\begin{tabular}{lcc}
\hline \multicolumn{1}{c}{ Karakteristik Demografi } & \multicolumn{2}{c}{ Skizofrenia } \\
\cline { 2 - 3 } & Frekuensi & Proporsi \% \\
\hline Kelompok Umur & 1 & 0.03 \\
Anak-anak (6-11 tahun) & 314 & 10.36 \\
Remaja (12-25 tahun) & 1759 & 58.01 \\
Dewasa (26-46 tahun) & 958 & 31.60 \\
Lansia (>46 tahun) & & \\
\hline Jenis Kelamin & 1035 & 34.14 \\
Perempuan & 1997 & 65.86 \\
Laki-laki & & \\
\hline Status Perkawinan & 1774 & 58.51 \\
Tidak Kawin & 1175 & 38.75 \\
Kawin & 83 & 2.74 \\
Cerai & & \\
\hline Pekerjaan & 2669 & 88.03 \\
Tidak Bekerja & 363 & 11.97 \\
Bekerja & & \\
\hline Pendidikan & 1003 & 33.08 \\
Tidak Sekolah & 718 & 23.68 \\
Tamat SD & 361 & 11.91 \\
Tamat SMP & 771 & 25.43 \\
Tamat SMA & 179 & 5.90 \\
Perguruan Tinggi & & \\
\hline Asal Pasien & 152 & 12.01 \\
Jemberana & 372 & \\
Tabanan & 292 & \\
Badung & & \\
Gianyar & & \\
\hline & & \\
\hline & & \\
\hline
\end{tabular}




\begin{tabular}{lcc}
\hline Klungkung & 198 & 6.53 \\
Bangli & 269 & 8.87 \\
Karangasem & 404 & 13.32 \\
Buleleng & 436 & 14.38 \\
Denpasar & 357 & 11.77 \\
Luar Bali & 70 & 2.31 \\
\hline
\end{tabular}

\section{PEMBAHASAN}

Selama Periode $2013-2018$ menunjukan bahwa pasien gangguan jiwa di Rumah Sakit Jiwa Provinsi Bali didominasi oleh pasien dengan diagnosa skizofrenia. Hal ini sejalan dengan pernyataan dari Nyoman Ari Yoga Wirawan dalam artikelnya yang berjudul "Karakteristik Demografi Pasien Depresi di Rumah Sakit Umum Pusat Sanglah Denpasar Bali, Periode 2011-2013" yang mengatakan bahwa gangguan jiwa dengan diagnosa skizofrenia lebih banyak ditemukan di rumah sakit, hal ini didasari oleh orang yang terdiagnosa skizofrenia memiliki tanda dan gejala yang jelas sehingga pelaporan lebih sering ke rumah sakit (Wirawan, 2016). Hal ini membuat pasien gangguan jiwa yang berobat ke RSJ Provinsi Bali didominasi oleh pasien gangguan jiwa diagnosa skizofrena.

Terjadinya trend yang menurun pada kunjungan pasien gangguan jiwa di RSJ Provinsi Bali dari tahun 2013 - 2016 disebabkan oleh berlakunya Undangundang No. 18 Tahun 2014 tentang Kesehatan Jiwa, dimana dalam undangundang tersebut pada Bab III tentang "sistem pelayanan kesehatan jiwa" pada pasal 33 ayat 1 dijelaskan bahwa pemerintah dalam melaksanakan upaya pelayanan kesehatan jiwa maka dibangun sistem kesehatan jiwa yang berjenjang dan komprehensif, yang terdiri atas pelayanan kesehatan jiwa dasar dan pelayanan kesehatan jiwa rujukan. Kesehatan jiwa dasar yang dimaksud adalah pelayanan kesehatan jiwa yang diselenggarakan terintegrasi dalam pelayanan kesehatan umum di Puskesmas dan jejaringnya, klinik pratama, praktik dokter dengan kompetensi pelayanan kesehatan jiwa, rumah perawatan, serta fasilitas pelayanan diluar sektor kesehatan dan fasilitas rehabilitasi berbasis masyarakat (Kemenkes, 2014). Dengan adanya sistem rujukan ini menyebabkan pasien gangguan jiwa terlebih dahulu mendapatkan penanganan di unit pelayanan kesehatan dasar, kemudian jika tidak mampu ditangani maka pasien selanjutnya dirujuk ke unit pelayanan kesehatan jiwa rujukan, baik unit pelayanan kesehatan jiwa di rumah sakit umum dimasing-masing Kabupaten/Kota di Bali atau unit pelayanan kesehatan jiwa di RSJ Provinsi Bali. Sehingga dengan adanya sistem pelayanan kesehatan jiwa pasien akan lebih banyak berobat di bagian unit pelayanan kesehatan dasar atau ke unit kesehatan jiwa di rumah sakit umum di masing-masing Kabupaten/Kota di Bali, selanjutnya jika tidak mampu ditangani maka rujukan terakhir adalah RSJ Provinsi Bali.

Selanjutnya dengan berlakunya Permenkes No. 39 tahun 2016 tentang 
Pedoman Penyelenggaraan Program Indonesia Sehat Berbasiskan Pendekatan Keluarga (PIS-PK) yang mana didalamnya terdapat 12 indikator, salah satu indikator yang ada dalam PIS-PK adalah penderita gangguan jiwa mendapatkan pengobatan dan tidak ditelantarkan. Dimana untuk mendukung keberhasilan dari indikator tersebut dilakukan beberapa kegiatan pendukung, yang diantaranya adalah meningkatkan akses pelayanan terpadu Penyakit Tidak Menular (PTM) di Fasilitas Kesehatan Tingkat Pertama (FKTP), serta promosi kesehatan tentang pengobatan dan perlakuan terhadap penderita gangguan jiwa. Sehingga dengan adanya program ini bisa meningkatkan pengetahuan masyarakat tentang gangguan jiwa skizofrenia dan membuat masyarakat yang memiliki anggota keluarga dengan gangguan jiwa mengajak anggota keluarganya berobat. Mengingat sistem berobat yang masih berjenjang karena orang dengan gangguan jiwa yang ditemukan sudah dalam kondisi yang parah sehingga membuat rujukan langsung ke RSJ Provinsi Bali sebagai rujukan akhir. Sehingga hal ini diduga penulis menjadi penyebab kenapa pasien baru skizofrenia yang ada di RSJ Provinsi Bali ditahun 2017 memiliki trend yang meningkat (Kemenkes, 2016).

Pada karakteristik umur pasien gangguan jiwa yang berobat di RSJ Provinsi Bali menunjukan bahwa gangguan jiwa dengan diagnosa skizofrenia paling banyak terjadi pada golongan umur dewasa yaitu dengan rentang umur 25 - 44 tahun. Sebanyak $58 \%$ dari pasien yang terdiagnosa skizofrenia merupakan pasien dengan golongan umur dewasa. Jika dilihat trend yang ada berdasarkan kelompok umur menunjukan bahwa trend gangguan jiwa dengan diagnosa skizofrenia secara umum mengalami penurunan, tetapi proporsi disetiap tahunnya masih didominasi oleh golongan umur dewasa. Hal ini menunjukan hasil yang sejalan dengan penelitian yang dilakukan oleh Handayani dan kawankawan pada tahun 2015 menunjukan bahwa sekitar $55.7 \%$ pada golongan umur dewasa (26 - 45 tahun), penelitian lain yang dilakukan oleh Kurnia dan kawan-kawan juga menunjukan bahwa ganguan jiwa dengan diagnosa skizofrenia masih didominasi dari golongan umur dewasa (26 - 45 tahun) yaitu sebesar 53.2\% (Kurnia, et al., 2015; Handayani, et al., 2015). Berdasarkan hasil penelitian yang dilakukan oleh Erlina mendapatkan hasil bawha umur yang memiliki risiko megalami gangguan jiwa dengan diagnosa skizofrenia adalah kelompok umur 25 - 35 tahun yaitu sebesar 1.8 kali dibandingkan dengan mereka yang berumur 17 - 24 tahun. Hal tersebut menjadi penyebab kenapa kunjungan di RSJ Provinsi Bali pada kasus gangguan jiwa dengan diagnosa skizofrenia didominasi dari golongan umur dewasa (Erlina, 2010).

Laki-laki lebih banyak mengalami skizofrenia pada kunjungan pasien gangguan jiwa di RSJ Provinsi Bali. Sebanyak $66 \%$ pasien gangguan jiwa dengan diagnosa skizofrenia didominasi oleh pasien dengan jenis kelamin laki-laki. Trend skizofrenia dilihat berdasarkan jenis kelamin baik laki-laki dan perempuan menunjukan penurunan trend dari tahun ketahun, dan proporsi jenis kelamin pada trend disetiap tahunnya didominasi oleh pasien skizofrenia berjenis kelamin laki-laki. Hal ini sejalan 
dengan beberapa peneltian yang diantaranya peneltian yang dilakukan oleh Adamo tahun 2017 menunjukan bahwa jenis kelamin yang lebih rentan mengalami gangguan jiwa dengan diagnosa skizofrenia adalah mereka yang memiliki jenis kelamin laki-laki (Adamo, 2007). Selain itu penelitian yang dilakukan oleh Erlina ditahun 2010 menunjukan bahwa pasien dengan jenis kelamin laki-laki lebih banyak ditemukan yaitu sebesar $72 \%$. Hal ini juga sejalan dengan pernyataan yang dikeluarkan oleh Cordosa dkk mengatakan bahwa laki-laki lebih sukar dalam menerima tekanan dibandingkan dengan perempuan (Cordosa, et al., 2005). Selain itu penelitian yang dilakukan oleh Agung Wahyudi pada tahun 2016 mendapatkan hasil bahwa proporsi pasien skizofrenia sebanyak $77.4 \%$ merupakan pasien yang memiliki latar belakang pendidikan rendah (Wahyudi \& Arulita, 2016).

Pada status perkawinan menunjukan bahwa mereka yang tidak kawin memiliki proporsi yang lebih banyak dibandingkan mereka yang kawin atau memiliki status perkawinan cerai. Dimana sebanyak 58\% pasien gangguan jiwa yang didiagnosa skizofrenia memiliki status perkawinan tidak kawin. Jika dilihat berdasarkan trend menunjukan bahwa pasien gangguan jiwa dengan diagnosa skizofrenia berdasarkan karakteristik status perkawinan mengalami trend penurunan pada mereka yang status perkawinanya tidak kawin dan kawin, serta pada mereka yang memiliki status perkawinan cerai mengalami trend yang fluktuatif, tetapi secara proporsi menunjukan status tidak kawin memiliki jumlah kasus tertinggi disetiap tahunnya.
Hal ini sejalan dengan pernyataan yang disampaikan oleh Simanjuntak orang yang tidak kawin lebih tinggi memiliki risiko terkena gangguan jiwa skizofrenia dibandingkan dengan mereka yang memiliki status perkawinan sudah kawin (Simanjuntak, 2008). Pada penelitian yang dilakukan oleh Wahyudi dan Arulita ditahun 2016 menunjukan bahwa mereka yang belum kawin memiliki risiko mengalami skizofrenia sebesar 4.747 kali dibandingkan dengan mereka yang kawin (Wahyudi \& Arulita, 2016). Dalam teori yang ada Buku Catatan Ilmu Kedokteran Jiwa karangan Maramis menyatakan pendapat bahwa status perkawinan dipandang perlu untuk melakukan pertukaran ego agar bisa mencapai kedamaian, selain itu perhatian dan kasih sayang merupakan hal yang sangat fundamental untuk mencapai suatu kehidupan yang berarti dan memuaskan (Maramis, 1994). Hal ini juga sejalan dengan teori yang disampaikan oleh Simanjuntak yang menyatakan bahwa mereka yang memiliki status perkawinan tidak kawin memiliki risiko mengalami gangguan jiwa dengan diagnosa skizofrenia dibandingkan mereka yang tidak kawin, hal ini disebabkan karena sebagian dari stressor psikososial disebabkan oleh status perkawinan (Simanjuntak, 2008).

Berdasarkan pekerjaan pada pasien gangguan jiwa dengan diagnosa skizofrenia terlihat bahwa mereka yang tidak bekerja memiliki jumlah yang lebih banyak dibandingkan dengan mereka yang bekerja. Hal tersebut masih perlu pendalaman pada variabel pekerjaan yang ada dalam penelitian ini terkait dengan status pekerjaan pasien yang dicatat, apakah status pekerjaan 
pasien setelah mengalami skizofrenia atau sebelum mengalami skizofrenia. Dilihat pada trend skizofrenia menunjukan adanya trend yang menurun pada pasien yang tidak bekerja, kemudian pada pasien yang memiliki pekerjaan mengalami peningkatan trend, namun secara proporsi status pekerjaan pasien skizofrenia didominasi pasien yang tidak bekerja. Sebanyak $88 \%$ dari 3032 pasien gangguan jiwa di RSJ Provinsi Bali yang terdiagnosa skizofrenia merupakan pasien yang tidak memiliki pekerjaan. Hal ini sejalan dengan penelitian yang dilakukan oleh Erlina, dimana dari hasil penelitiannya didapatkan bahwa mereka yang tidak bekerja memiliki risiko mengalami skizofrenia sebesar 6.2 kali dibandingkan mereka yang bekerja. Hal ini sesuai dengan pernyataan yang ada dalam Buku Kesehatan Mental 3, dimana jika seseorang yang tidak bekerja dapat menimbulkan beberapa hal seperti stress, depresi dan mengalami pelemahan pada kejiwaan sehingga menyebabkan seseorang yang tidak bekerja merasa tidak berdaya dan pesimis terhadap masa depan, tentu hal ini yang menjadi faktor risiko seseorang bisa mengalami gangguan jiwa dengan diagnosa skizofrenia. Penelitian ini sejalan dengan penelitian yang dilakukan Erlina dkk (2010) dimana dalam hasil penelitiannya menunjukan bahwa terdapat hubungan antara status ekonomi rendah dengan kejadian gangguan jiwa skizofrenia dengan OR sebesar 6.00. Selain itu pendapat dari Jean dan Canto menunjukan bahwa terdapat faktor-faktor psikososial yang dapat mempengaruhi seseorang bisa mengalami gangguan jiwa skizofrenia yang diantaranya adalah status ekonomi yang rendah dan juga stress akibat lingkungan (Jean \& Canto,
2005). Penelitian yang sejalan juga dilakukan oleh Mallet dkk pada tahun 2002 menunjukan bahwa terdapat hubungan yang bermakna antara status pekerjaan dengan munculnya kejadian skizofrenia (Mallet, et al., 2002). Hal ini disebabkan karena stress akan lebih mudah terjadi pada orang yang tidak memiliki pekerjaan, hal ini disebabkan oleh orang yang stress akan lebih banyak memproduksi hormon stress (kadar katekolamin), serta orang yang tidak memiliki pekerjaan akan merasa tidak berdaya karena selalu masa pesimis dan tidak semangat memandang masa depan (Erlina, 2010). Selain itu menurut Bartley kondisi seseorang yang menganggur dapat merusak kesehatan seseorang secara umum dan hal ini bisa menjadi penyebab seseorang yang menganggur atau tidak bekerja bisa mengalami gangguan jiwa (Bartley, 2010).

Pendidikan terakhir pasien skizofrenia di RSJ Provinsi Bali selama 6 tahun terakhir menunjukan hasil bahwa jenjang pendidikan paling banyak mengalami gangguan jiwa dengan diagnosa skizofrenia pada mereka yang tidak bersekolah. Trend skizofrenia berdasarkan pendidikan menunjukan bahwa terdapat trend serupa pada mereka yang memiliki tingkat pendidikan tidak sekolah dan SD memiliki jumlah kasus yang hampir sama dengan mereka yang tingkat pendidikannya SMA. Sebanyak 33\% mereka yang tidak bersekolah atau memiliki latar belakang pendidikan rendah mengalami gangguan jiwa dengan diagnosa skizofrenia. Hal ini sejalan dengan penelitian yang dilakukan oleh Yanuar pada tahun 2011 bahwa gangguan jiwa dengan diagnosa skizofrenia lebih banyak didominasi pada mereka yang 
berlatar belakang pendidikan rendah (Yanuar, 2011). Hasil penelitian yang ditemukan oleh Fakhry dan kawan-kawan pada tahun 2005 mendapatkan hasil dalam penelitiannya mengatakan terdapat hubungan yang bermakna antara pendidikan yang rendah atau tidak punya pendidikan dengan timbulnya gangguan jiwa skizofrenia (Fakhri, et al., 2005).

Menurut karakteristik asal pasien menunjukan bahwa pasien skizofrenia sebanyak $16 \%$ berasal dari Kabupaten Gianyar. Sedangkan jika dilihat berdasarkan sebaran kasus dapat dilihat terdapat 5 Kabupaten/Kota yang berada dalam kategori merah yaitu Kabupaten Buleleng, Karangasem, Tabanan, Gianyar dan Kota Denpasar. Berdasarkan sebaran kasus menunjukan bahwa daerah yang berwarna merah atau dengan kategori 3 merupakan 5 besar daerah yang memiliki penduduk miskin, dimana data Badan Pusat Statistik terkait dengan jumlah penduduk miskin Provinsi Bali berdasarkan Kabupaten Kota selama 6 tahun terakhir didapatkan 5 Kabupaten Kota yang paling banyak memiliki penduduk miskin adalah Kabupaten Buleleng, Karangasem, Tabanan, Gianyar dan Kota Denpasar (Badan Pusat Statistik, 2018). Hal ini sejalan dengan teori yang disampaikan teori yang disampaikan oleh (Pravitasari, 2015; Videbeck, 2015) terkait dengan faktor lingkungan sebagai penyebab orang bisa mengalami gangguan jiwa khususnya skizofrenia, pada penderita skizofrenia dikenal dengan istilah down word drift (orang yang terkena skizofrenia bergeser ke kelompok sosial ekonomi rendah atau gagal keluar dari sosial ekonomi rendah). Social drift hipotesis menyatakan bahwa seseorang yang menderita skizofrenia bergantung kepada lingkungan disekitarnya, kehilangan pekerjaan dan berkurangnya penghasilan. Jika dikaitkan dengan teori ini dengan sebaran kejadian skizofrenia, kemiskinan menjadi salah satu penyebab 5 Kabupaten/ Kota di Bali berada dalam zona merah. Hal ini bisa terjadi karena rendahnya tingkat pendidikan, atau susahnya mencari pekerjaan sehingga membuat status ekonomi menjadi rendah dan bisa memicu terjadinya stress.

Dalam penelitian ini terdapat beberapa kelemahan-kelemahan yang menjadi faktor penentu hasil dari penelitian kurang optimal. Dalam penelitian ini karena menggunakan data Sekunder maka data yang didapat menjadi kurang lengkap, sehingga hasil dalam penelitian ini menjadi kurang optimal. Dalam penelitian ini masih kurangnya literature yang baru sehingga menyebabkan penulis mengalami kesulitan dalam mencari bahan bacaan sebagai penuntun penulis dalam menulis.

\section{SIMPULAN}

Pasien gangguan jiwa baru di RSJ Provinsi Bali yang tercatat dalam Data Register Rumah Sakit Jiwa Provinsi Bali selama 6 tahun terakhir berjumlah 4737 pasien dimana $64 \%$ nya merupakan pasien dengan diagnosa skizofrenia. Berdasarkan pada trend gangguan jiwa menunjukan bahwa trend gangguan jiwa dengan diagnosa skizofrenia dari tahun 2013 -2016 mengalami penurunan, kemudian ditahun 2017 trend mengalami peningkatan dan ditahun 2018 trend kembali mengalami penurunan. 


\section{SARAN}

Guna mendata pasien gangguan jiwa baik di tingkat layanan dasar maupun layanan rujukan sehingga dibutuhkan penguatan sistem surveilans/ sistem pencatatan dan pelaporan yang baik dan terintegrasi yang dilaksanakan oleh Rumah Sakit Jiwa Provinsi Bali. Penguatan sistem pencatatan dan pelaporan yang baik yang dimaksud adalah pencatatan dan pelaporan kasus baru, jumlah kunjungan serta pada sistem rujuk balik.

\section{DAFTAR PUSTAKA}

Adamo, J. P., (2007), The Genotype Diet. Jakarta: Gramedia Pustaka Utama.

Badan Pusat Statistik, (2018), bali.bps.go.id. [Online] Available at: https://bali.bps.go.id/ dynamictable/2018/02/14/228/jumlahpenduduk-miskin-provinsi-balimenurut-kabupaten-kota-20022016.html

Bartley, M., (2010), Pengangguran dan Kesehatan yang buruk ; memahami hubungan. Jurnal Epidemiologi dan Kesehatan Masyarakat, pp. 333-338.

Cordosa, S. C. et al., (2005), Factor's Associated with Low Quality of Life in Schizofrenia. p. http:// www.scielo.br/pdf/csp/v21n5/05.pdf.

Erlina, (2010), Determinan Terhadap Timbulnya Skizofrenia pada Pasien Rawat Jalan di Rumah Sakit Jiwa Prof. HB Saanin Padang Sumatera Barat. Berita Kedokteran Masyarakat, pp. 7180.
Fakhri, A., Ranjabar, F., Dadashzadeh \& Moghaddas, F., (2005), Epidemiological Survey of Mental Disosders Among Adult In The North, West Area of Tabriz. Departement Of Psychiatry.

Handayani, L., Febriani, Aprilia, R. \& Azidanti, S., (2015), Faktor Risiko Skizofrenia di RSJ Grahasia DIY. Humanitas, pp. 135-148.

Jean, P. \& Canto, E., (2005), Social Defeat: Risk Factor Of Schizophrenia. British Journal Of Psychiatry, pp. 101-102.

Kemenkes, (2014), Undang-Undang Republik Indonesia No 18 Tahun 2014 tentang Kesehatan Jiwa. Jakarta: s.n.

Kemenkes, (2016), Permenkes No 39 Tahun 2016 tentang Pedoman Penyelenggaraan PIS-PK. Jakarta: Kementerian Kesehatan.

Kurnia, F. Y. P., Tyaswati, E. J. \& Abrori, C., (2015), Faktor-faktor yang Mempengaruhi Kekambuhan pada Pasien Skizofrenia di RSD dr. Soebandi Jember. e-Jurnal Pustaka Kesehatan, pp. 400-407.

Mallet, R. et al., (2002), Environment, Ethnicity and Schizofrenia. Institute Of Psychiatri.

Maramis, W. F., (1994), Catatan Ilmu Kedokteran Jiwa. Surabaya: Airlangga University Press.

Pravitasari, G. A., (2015), Gambaran Manajemen Gejala Halusinasi pada Orang dengan Skizofrenia (ODS) di Ruang Rawat Inap RSJD Dr. Amino 
Gondohutomo, Semarang: Universitas Diponegoro.

Simanjuntak, J., (2008), Konseling Gangguan Jiwa dan Okultisme. Jakarta: Gramedia Pustaka Utama.

Videbeck, S. L., (2015), Buku Ajar Keperawatan Jiwa. Jakarta: EGC.

Wahyudi, A. \& Arulita, F. I., (2016), Risk Factor Of Skizofrenia (Studi Kasus di Wilayah Kerja Puskesmas Pati II). Public Health Perspective Journal, p. 6.

WHO, (2011), The World Report : Mental Health : New Understanding New Hope, Geneva: s.n.
Wirawan, N. A. Y., (2016), Karakteristik Demografi Pasien Depresi di Rumah Sakit Umum Pusat Sanglah Denpasar Bali Periode 2011-2013. Intisari Sains Medis, pp. 6-11.

Yanuar, R., (2011), Analisis Faktor yang Berhubungan dengan Kejadian Gangguan Jiwa di Desa Paringan Kecamatan Jenangan Kabupaten Ponorogo, Surabaya: Universitas Airlangga. 